\section{The SHORT syndrome: further delineation and natural history}

The sixth reported case of the SHORT syndrome is described and is compared with other cases. The child (figs 1 and 2), small with normal growth hormone production, had a striking absence of subcutaneous fat, a triangular shaped, broad forehead, small chin, megalocornea and anterior segment dystrophy of the eye, bilateral clinodactyly, and normal intellectual development. The child was initially thought to have the Silver-Russell syndrome.

The proband, now aged 10, was born at 38 weeks' gestation weighing $2200 \mathrm{~g}$ with a length of $48.3 \mathrm{~cm}$. The father was aged 21 and the mother 18 at his birth and they were non-consanguineous, white Australians. There was no family history of dwarfism or birth defects. The paternal grandmother has insulin dependent diabetes and is $160 \mathrm{~cm}$ tall.

A striking absence of subcutaneous fat, particularly in the face, first noted at the age of three months, has persisted and now includes the shoulders and chest. He has

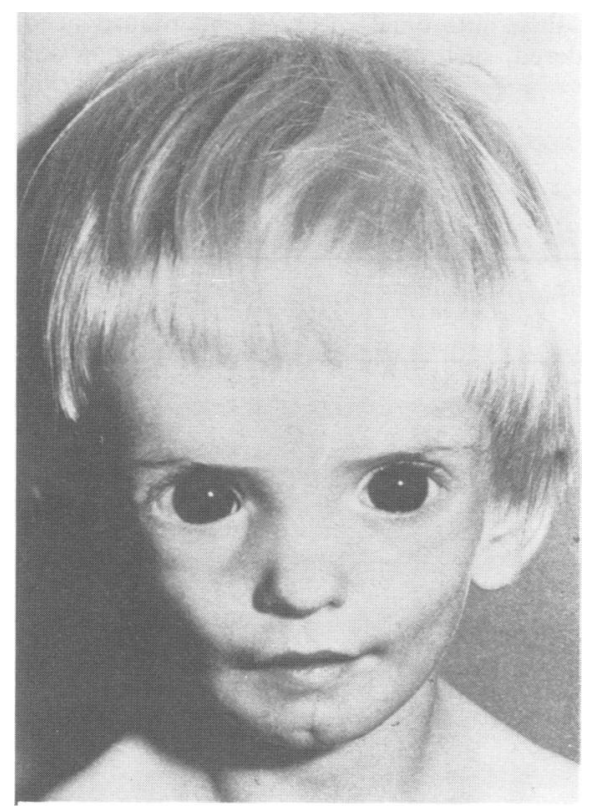

FIG 1 The proband aged five months. Note similarity to the case of Gorlin et al (fig 3).

Received for publication 17 October 1988

Revised version accepted for publication 3 February 1989. one sib, a boy aged three who is well. The patient had recurrent vomiting and feeding problems until the age of two years. Height and weight have always been well below the 3 rd centile. Height velocity is normal. Head circumference has been maintained at the 10th centile since an early age. Tooth eruption was delayed until 12 months. On examination at the age of nine years nine months, head circumference was $50.5 \mathrm{~cm}$ (10th centile), height $120.9 \mathrm{~cm}$ ( $<3$ rd centile), and weight $18.7 \mathrm{~kg}$ ( $<3$ rd centile). There was absence of subcutaneous tissue, particularly around the chest and face. The skin generally seemed thin and transparent. The face was triangular with a small, relatively pointed lower jaw with a vertical groove and dimple, which he shares with both his father and grandfather. There was maxillary hypoplasia and the forehead appeared

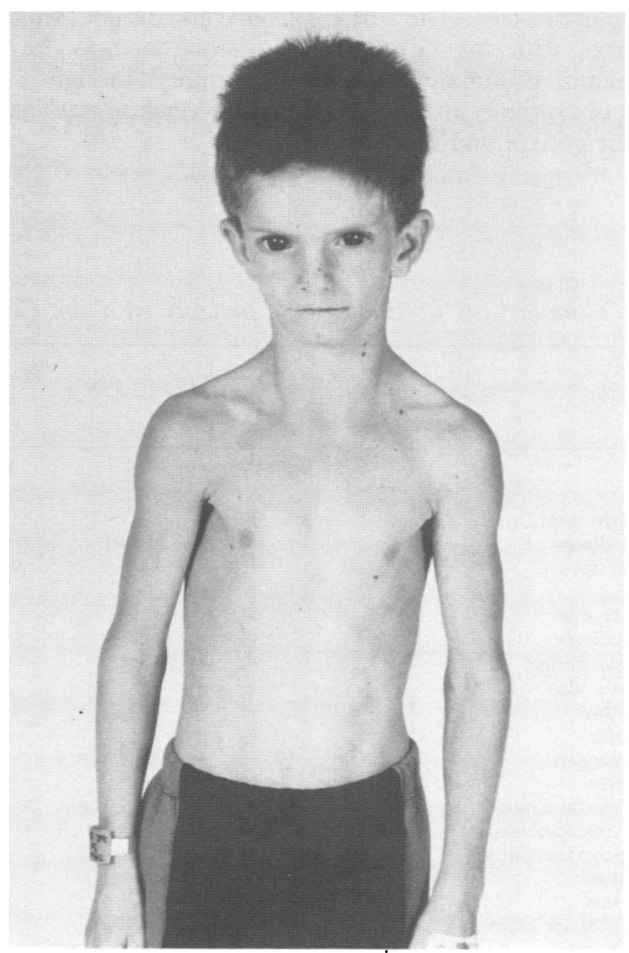

FIG 2 The proband aged nine years. Note lack of subcutaneous fat on face and body, triangular face, hypoplastic mandible, and anteverted ears. 
broad. He had bilateral clinodactyly. There were no café au lait patches, body asymmetry, or other anomalies. Initial diagnosis was the Silver-Russell syndrome.

Ophthalmological examination showed unusual irides owing to almost total absence of the anterior stromal layer. The posterior pigmented layer was exposed. Corneal diameter was $13 \times 13 \mathrm{~cm}$ (normal $11 \cdot 5 \pm 0 \cdot 5 \mathrm{~cm}$ ). Intraocular pressure and fundi were normal.

Extensive endocrinological investigation including growth hormone levels after clonidine, sleep, and exercise stimulation was normal. Thyroid function studies, somatomedin, CT scan, and extensive biochemical investigations showed no abnormalities. He attends normal school where he manages appropriately for his age. However, his small size and unusual appearance have created some adjustment difficulties.

Gorlin et al $^{1}$ described an apparently new syndrome in brothers and gave it the acronym of 'SHORT' as follows: S-short stature, H-hyperextensibility of joints or hernia, O-ocular depression, $\mathrm{R}$-Rieger anomaly, $\mathrm{T}$-teething (delay).

This boy has striking similarities to Gorlin's original cases (fig 3) and to the case of Toriello et al (table). The syndrome of partial lipodystrophy, Rieger anomaly, short stature, and insulinopenic diabetes inherited dominantly may be a diagnosis, this case representing a mutant. ${ }^{4}$ Only one of the cases of Aarskog et $a l^{4}$ developed insulin dependent diabetes at the age of 39 . Diabetes may still develop in this case. The vertical groove and dimple, which he shares with his father and grandfather, may be a coincidental dominantly inherited feature, ${ }^{5}$ though the patient of Gorlin et al (fig 3) and that of Aarskog et al ${ }^{4}$ had a similar groove and dimple.

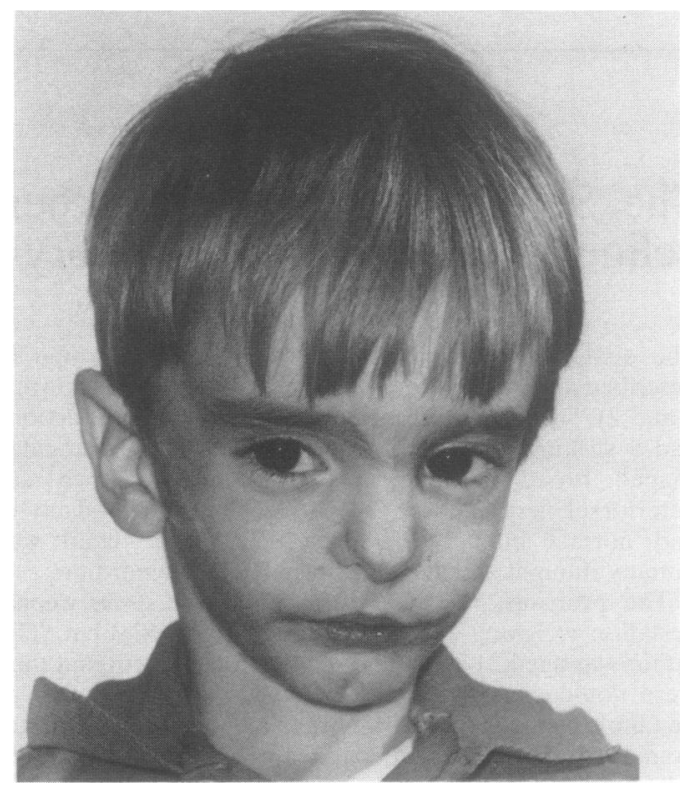

FIG 3 Case 1 of Gorlin et al (by permission). Note hypoplastic alae and chin dimple.

In families with two affected infants, as in the cases of Gorlin et al, ${ }^{1}$ who are born to normal parents, explanations other than autosomal recessive inheritance need to be considered, such as variable expression of an autosomal

TABLE Comparison of findings in patients with the SHORT syndrome.

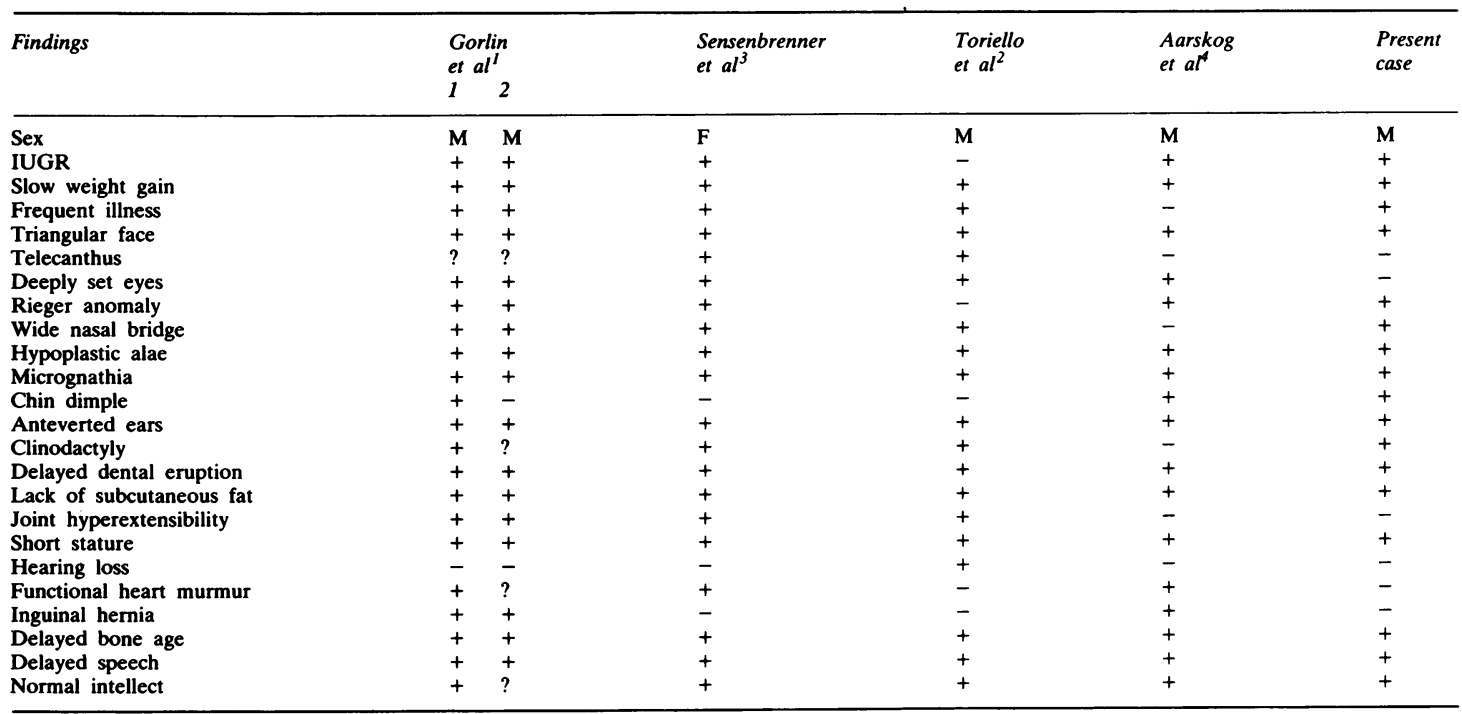


dominant gene or germinal mosaicism for an autosomal dominant disorder. ${ }^{6}$

The heritability of this condition remains uncertain.

We thank Angie Mavromihalis for secretarial assistance.

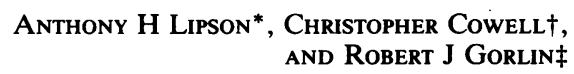

*Genetics and Dysmorphology Unit, and Institute of Endocrinology, The Children's Hospital, Camperdown, Sydney, Australia; and $\ddagger$ the Department of Oral Pathology and Genetics, University of Minnesota, Minneapolis, USA.

\section{References}

1 Gorlin RJ, Cervenka J, Moller K, Horrobin M, Witkop CJ. Rieger anomaly and growth retardation (the S-H-O-R-T syndrome). In: Bergsma D, ed. Malformation syndromes. New York: Excerpta Medica for the National Foundation-March of Dimes, 1975:46-8.
2 Toriello HV, Wakefield S, Komar K, Higgins JV, Waterman DF. Report of a case and further delineation of the SHORT syndrome. Am J Med Genet 1985;22:311-4.

${ }^{3}$ Sensenbrenner JA, Hussels IE, Levin LS. CC-a low birthweight syndrome? Reiger syndrome. In: Bergsma D, ed. Malformation syndromes. New York: Excerpta Medica for the National Foundation-March of Dimes, 1975:423-6.

4 Aarskog D, Ose L, Pande H, Eide N. Autosomal dominant partial lipodystrophy associated with Rieger anomaly, short stature, and insulinopenic diabetes. Am J Med Genet 1983;15: 29-38.

5 Hall BD. Chin dimples (chin clefts): demonstration of autosomal dominant inheritance in a 5 generation family. Próc Greenwood Genet Center 1988;7:220-1.

${ }^{6}$ Hall JG, Byers PH. Genetics of tuberous sclerosis. Lancet 1987;i:751.

Correspondence to Dr Anthony $\mathrm{H}$ Lipson, Genetics and Dysmorphology Unit, The Children's Hospital, PO Box 34, Camperdown, NSW 2050, Australia. 